\title{
Reflejo De La Psicología Revolucionaria En El Comportamiento Del Individuo En Las Obras Literarias De Mariano Azuela E Isaac Bábel
}

\author{
Julia Sadovska \\ Universidad Nacional Ilia Mechnikov de Odesa Ucrania, Ukraine
}

Doi:10.19044/esj.2018.v14n17p80 ＵRL:http://dx.doi.org/10.19044/esj.2018.v14n17p80

\begin{abstract}
This paper focuses on the analysis of the psychology and the model of human behavior reflected in the works of M. Azuela and I. Babel. The novels "The ones of down" (M. Azuela) and "Red Cavalry" (I. Babel), dedicated to the revolution and the civil war, are explored within the framework of the social psychology. Theories of human behavior in the revolution, the aspect of motivation, and the socio-psychological mechanisms of its massive impact on the individual are considered. Similarly, the state of emotional stress that forces the masses to move was investigated. In the process of the "emotional whirlpool" and the "circular reaction" in progress, the voltage increases, which inevitably result to an explosion at the end (most of the time - of a violent nature). The parallel analysis of the researched works reveals that human behavior is determined by belonging to the consciousness of the masses or to the individual conscience. Individual consciousness and mass exist in a certain unity, but mass psychology, conquers the individual. In this case, a person becomes the "bearer of the mask" of the revolution.
\end{abstract}

Keywords: Revolutionary psychology, collective consciousness, individual conscience, Mariano Azuela, Isaac Bábel

\section{Resumen}

Este artículo está dedicado al análisis de la psicología y el modelo del comportamiento humano reflejado en las obras de M. Azuela e I. Babel. Las novelas "Los de abajo" (M. Azuela) y " Caballería Roja " (I. Babel), dedicadas a la revolución y la guerra civil, son exploradas en el marco de la psicología social. Se consideran las teorías del comportamiento humano en la revolución, el aspecto de la motivación y los mecanismos sociopsicológicos del impacto masivo en el individuo. De igual manera, se investiga el estado del estrés emocional que obliga a las masas a moverse. En 
el proceso del "remolino emocional" y la "reacción circular" en curso, el voltaje aumenta, lo que al final conduce inevitablemente a una explosión (la mayoría de las veces - de naturaleza violenta). El análisis paralelo de las obras investigadas revela que la conducta humana está determinada por la pertenencia a la conciencia de las masas o a la conciencia individual. La conciencia individual y la masa existen en cierta unidad, pero la psicología masiva conquista al individuo. En este caso, una persona se convierte en "la portadora de la máscara" de la revolución.

Palabras clave: psicología revolucionaria, conciencia colectiva, conciencia individual, Mariano Azuela, Isaac Bábel

\section{Introducción}

La vigencia del presente estudio está condicionada por las características de la realidad histórica que estamos viviendo. Este es un período de auge de la conciencia insurreccional y de una aspiración generalizada a transformaciones sociales. Personas envueltas en situaciones de perturbaciones políticas forman parte de nuestra vida cotidiana. Sus procesos cognitivos, sus esperanzas de un futuro mejor no dejan de conmovernos y preocuparnos. Mientras tanto, la psicología de estos individuos y sus modelos conductuales ya han sido reflejados en toda una serie de obras literarias dedicadas al tema de la revolución, desde la literatura rusa post-revolucionaria, con su claro mensaje ideológico, hasta las numerosas novelas de revolución de autores latinoamericanos.

Después de haber analizado la novela Los de abajo de Mariano Azuela y Caballería Roja, colección de cuentos de Isaac Bábel, y teniendo en cuenta las características nacionales específicas de la percepción de los acontecimientos y las particularidades de su representación artística, podemos señalar una afinidad conceptual entre estos escritores en cuanto a la recreación de los mecanismos psicológicos y modelos del comportamiento de una persona dentro del proceso revolucionario. Por ello hemos fijado como objetivo del presente estudio un análisis paralelo de dichas obras literarias enfocado en el aspecto del problema antes mencionado.

\section{Texto principal}

La interpretación artística de la realidad revolucionaria responde a un vivo interés, generalmente existente, por la representación del estado psicológico de una persona durante los acontecimientos revolucionarios.

Los investigadores modernos de psicología social señalan que existen dos teorías que interpretan el comportamiento del individuo en medio de una revolución. Según la primera (Gustave Le Bon, William McDougall), la participación del individuo en actividades revolucionarias, su integración a la 
multitud o a un movimiento colectivo, es una manifestación de su irracionalidad, agresividad y propensión a la violencia: el impulso ciego, brutal de la éxtasis revolucionaria lo destruye todo (Yurevych, 2007). Es decir, la persona que depende psicológicamente de la multitud se convierte en un portador de la "conciencia colectiva".

Algunos teóricos contemporáneos que se dedican a investigar el fenómeno de la revolución (Mancur Olson, Michael Kimmel) oponen a la idea de una absoluta espontaneidad e irracionalidad de las masas revolucionarias una visión diferente, según la cual puede tratarse de un comportamiento completamente racional que persigue determinados intereses, de grupo o personales. Interpretan el modelo conductual del individuo dentro de una revolución como una reacción racional a unas circunstancias sociales irracionales: las ideas y las emociones son analizadas dentro de un contexto social; los cambios estructurales que se operan en la sociedad crean bases para una conducta revolucionaria que al principio no es más que una manifestación de la furia ciega de la multitud, pero luego adquiere un carácter racional y comprensible; por eso los motivos de la conducta revolucionaria no pueden ser reducidos a la naturaleza irracional y destructiva del individuo (Olshanskyj, 2001). Se puede afirmar que este tipo de conducta es propio de los portadores de la conciencia individual.

Analicemos, pues, ejemplos concretos: la novela Los de abajo de Mariano Azuela y la colección de cuentos Caballería Roja de Isaac Bábel.

El mexicano Mariano Azuela describe un multitudinario movimiento popular por primera vez en la literatura latinoamericana: su novela Los de abajo narra la historia de la gesta espontánea de un grupo de rebeldes. El carácter de la narración asemeja la novela a los tradicionales corridos mexicanos: el autor retrata vívidamente el entusiasmo y la impresionante fuerza de la masa popular, en pocas palabras, su avance incontenible. Una pequeña tropa de villistas (casi todos antiguos campesinos) encabezada por el también campesino Demetrio Macías avanza poseída por un impulso común, convirtiéndose en la imagen de una indomable fuerza tectónica que se alza desde lo más profundo de las masas populares. La tropa de rebeldes se percibe como una parte de una gran corriente revolucionaria, de la masa unida por el odio al opresor, por la desesperación y por un pasado cargado de humillación y miseria.

En este caso, la conciencia colectiva se manifiesta en el comportamiento de las masas, espontáneo, irracional y desorganizado. El autor se siente fascinado por el ritmo palpitante de la lucha, y al mismo tiempo demuestra cómo los primeros éxitos de los rebeldes se ven minimizados por los fracasos ulteriores. Una masa descontrolada es lo suficientemente fuerte para arrasar con cuanto encuentre a su paso, pero es incapaz de crear un mundo nuevo, construir una nueva sociedad. 
El lúcido realismo con que el autor refleja la fuerza espontánea de la rebelión popular, el tenso dinamismo de la acción basado en detalles escuetos y precisos; todos estos rasgos innovadores que caracterizan la prosa del escritor mexicano convirtieron las obras de Mariano Azuela en un significante fenómeno en el ámbito literario internacional.

En lo que respecta al modo en que este autor recrea un incontrolable movimiento de las masas revolucionarias, es importante señalar que Azuela muestra afinidad con la obra de Isaac Bábel.Caballería Roja de Bábel aborda temas similares (revolución, frentes de la guerra civil, rebelión, un movimiento espontáneo de masas visto como una corriente del pueblo). Los cuentos que forman parte de la colección presentan la revolución como una incontenible fuerza natural, y esta visión es muy semejante a la que ofrece el autor de la epopeya mexicana. Según Mariano Azuela, la historia de sus personajes está marcada por la "danza macabra de la verdad y la mentira", es una intrínseca unión de lo sublime y lo mezquino; son los mismos elementos que integran el mundo artístico de Caballería Roja.

Para Isaac Bábel la praxis revolucionaria es una lucha encarnizada, cruel y sangrienta. Bábel no abriga ilusiones románticas respecto a la guerra. "Una revolución no puede dejar de disparar porque es una revolución" (Babel, 2013, p. 25), señala Bábel. Ríos de sangre, residuos de pólvora flotando en el aire; este es el escenario que genera una realidad fantasmal, ilusoria, en la cual un combatiente del Primer Ejército de Caballería Roja se funde con su caballo y luego la imagen de este "centauro" se disuelve en la multitud.

Para representar el carácter espontáneo, incontrolable de las masas, Azuela y Bábel escogen las mismas manifestaciones, muy características, de la praxis revolucionaria. El lector es testigo de mítines, marchas, combates, de manifestaciones de rebeldía colectiva, impulsos anárquicos e irracionales.

Entre las diferentes tendencias de interpretación psicológica del comportamiento de los individuos dentro del proceso revolucionario, el análisis del divorcio existente entre la realidad y la esperanza se merece una atención especial. Una de las interpretaciones de las consecuencias de esta divergencia se basa en la teoría de la interrelación entre la frustración y la agresión (teoría de Neal Elgar Miller y John Dollard); según esta teoría, las expectativas que no se llegan a cumplir provocan frustración y esta a su vez origina agresión, que se manifiesta en el comportamiento de los representantes de la conciencia colectiva.

El impulso colectivo descrito en Los de abajo y Caballería Roja es a menudo acompañado de una destrucción irracional y despiadada. El triunfo de la barbarie, que se traduce en saqueos y asesinatos, demuestra, según los autores de estas obras, la trágica predeterminación fatal que condena al fracaso a la rebelión colectiva. 
Podemos afirmar que ambos escritores, el mexicano y el ruso, demuestran que grandes agrupaciones de gente, unidas por un espontáneo impulso colectivo, no son capaces de actuar de una manera organizada y racional. La masa no procura concientizar la situación en la que se encuentra ni planear el futuro. La conducta impulsiva, la impotencia, la incapacidad de tomar conciencia de los objetivos de la revolución son rasgos característicos de los portadores de la conciencia colectiva. Como consecuencia, a "los de abajo" les toca ser engañados por "los de arriba", que se aprovechan de los logros de las transformaciones revolucionarias.

En los textos que analizamos, se muestra cómo de la masa emergen individuos que, por una parte, están compenetrados con ella, pero por otra parte, en el plano individual, se le oponen. Son portadores de la conciencia individual.

La masa influye en el individuo y modifica su manera de ser. Uno de los más importantes mecanismos socio-psicológicos de la influencia de la masa en el individuo es la así llamada "reacción circular" (Olshanskyj, 2001) que logra borrar temporalmente las peculiaridades individuales y transforma un conjunto de individuos aislados en una avalancha humana.

Una emoción u otra, compartida y reproducida por numerosos seguidores, como regla, vuelve a los generadores de la idea, creando una especie de movimiento de trayectoria circular. En el proceso de la integración de nuevos miembros a la comunidad, la emoción vuelve a recrearse una y otra vez, lo cual garantiza una inducción de dicho estado psicofísico. La esencia de este "remolino emocional" (Olshanskyj, 2001) es sencilla: en una comunidad surgida espontáneamente, una emoción u otra, múltiplemente repetida, se refuerza a sí misma (puede ser tanto una emoción del impulso colectivo para avanzar hacia un futuro digno como una emoción que conduce a actos de violencia, a la crueldad y el merodeo) (Mariano Azuela, Los de abajo; Isaac Bábel, Caballería Roja).

El estado de tensión emocional obliga a las masas a moverse. En el proceso de "remolino emocional" y de una prolongada reacción circular, la tensión va creciendo progresivamente, lo cual a la larga inevitablemente provoca una explosión (como regla, de índole violenta).

La masa borra diferencias grupales e individuales entre las personas, transforma su psiquis, imponiéndose a la conciencia individual. Pero la masa no sólo "despoja" de algo al individuo, sino que también le confiere nuevas características; por ejemplo, una sensación de poder invencible, una impunidad provocada por el obvio anonimato del individuo dentro de la multitud, anonimato que genera irresponsabilidad y la sugestionabilidad.

Mariano Azuela e Isaac Bábel exploran el estado psíquico de la masa de una manera minuciosa y detallada, creando una gran cantidad de personajes anónimos. Al mismo tiempo, los autores destacan imágenes 
concretas de revolucionarios (Demetrio, Liútov), dotándolas de características individuales. Estos personajes no llegan a disolverse definitivamente en la multitud, pero cuando llega la hora del impulso colectivo, pasan a formar parte de la masa; es entonces cuando se borran los límites entre las personalidades que se funden en un todo único. O sea, todos estos personajes carecen de importancia propia, su destino es integrarse a la imagen general de la corriente.

En otras palabras, las principales características de un individuo influenciado por la masa son: la desaparición de la personalidad consciente (que cede lugar a la inconsciente), la orientación de los pensamientos y emociones de varios individuos en la misma dirección como consecuencia de sugestión y contagio y una tendencia a la urgente y precipitada transformación de una idea impuesta en un acto. Como consecuencia, "el individuo deja de ser uno mismo, se convierte en un autómata carente de voluntad propia".

En los cuentos de Bábel, Liútov, corresponsal del periódico Jinete rojo, encarna una personalidad singular, con plena conciencia del valor del yo aislado. Pero al final esta personalidad deja de resistir y se rinde ante la masa. La solitaria voz humana se apaga absorbida por un mar de otras voces; un individuo sólo se toma en cuenta cuando representa el sentir de "todos".

En la novela Los de abajo Demetrio, el jefe de la partida de los rebeldes, se destaca entre la multitud; es capaz de movilizarla y encabezar la lucha. Pero a diferencia de Liútov, Demetrio no se percibe a sí mismo como una personalidad excepcional. Está ligado al pueblo de una manera orgánica y natural, es la encarnación unipersonal de la conciencia colectiva.

Uno de los problemas fundamentales que surgen en el proceso del estudio de la psicología del comportamiento revolucionario es el problema de la motivación, de las razones que obligan al individuo a abandonar la vida pacífica para incorporarse al movimiento revolucionario. Michael Kimmel señala que en este caso existen dos principales fuentes de motivación: la desesperación y la esperanza (la desesperación generada por la vida bajo el régimen existente y la esperanza de que todo cambie para mejor) (Kimmel, 1990).

Al mismo tiempo, existen contradicciones entre la motivación de la praxis revolucionaria, por una parte, y sus fines y objetivos, por otra. Esto se debe al hecho de que los revolucionarios no siempre están conscientes de lo que esperan de la revolución; sus motivos, como regla, son bastante complejos y no siempre se prestan a una explicación racional.

Este tipo de motivación "vaga" por lo general es propia de los representantes de la intelectualidad, portadores de la conciencia individual. Luis Cervantes, un típico intelectual de origen burgués (Los de abajo), percibe la revolución como un escenario perfecto para una gran hazaña, 
envuelto en nubarrones de pólvora quemada y aureolado por la gloria de intrépidos guerreros; el lado oscuro de la revolución pasa a un segundo plano. Es evidente la tendencia de Cervantes a exagerar y heroizar su propia participación en el proceso, pero la dura rutina de la guerra termina por desgastar sus ilusiones románticas. Es un personaje interiormente escindido, su actitud ante la revolución es ambivalente; sus contradicciones internas se traducen en un divorcio enfermizo entre sus ambiciones de héroe y la cobardía que pretende esconder.

La realidad abre sus ojos a lo infundado de su ideal y al desvanecimiento de su misión: "Yo pensé una florida pradera al remate de un camino... Y me encontré un pantano. Amigo mio: hay hechos y hay hombres que no son sino pura hiel. Y esa hiel va cayendo gota a gota en el alma, y todo lo amarga, todo lo envenena. Entusiasmo, esperanzas, ideales, alegrias» (Azuela, 1997, p.60).

Cervantes, por muy hipócrita que sea su conducta, no busca una ilusoria justificación moral a sus hechos. Los prejuicios propios de un portador de la conciencia de masas ("es imposible reivindicar la dignidad humana y alcanzar la justicia prescindiendo de la violencia") entran en este caso en contradicción con la naturaleza de la intelectualidad, que no es una fuerza espontánea ni destructiva. ¿Pueden los intelectuales considerarse "compañeros de ruta" de la masa? Si nos referimos al período revolucionario la respuesta va a ser "sí". Sin embargo, al mismo tiempo, un intelectual no vive de la utopía de una revolución "pura". El caos social reinante, la falta de una sólida visión histórica y la ansiedad por un futuro incierto y amenazador provocan una contradicción interna entre las fantasías románticas de gesta y hazañas y la brutal realidad de la praxis revolucionaria. La tragedia de un intelectual radica en la imposibilidad de la solución de este conflicto, ya que un intelectual, por su naturaleza, es incapaz de abstraerse del conflicto y limitarse a observarlo pasivamente.

Así pues, la exaltación social de los representantes de la conciencia individual y sus ilusiones respecto al proceso revolucionario no tardan en transformarse en desesperación y desilusión; las contradicciones internas que caracterizan su percepción de la ideología revolucionaria provocan una nivelación de la personalidad y a la larga convierten a estos personajes en "enemigos enmascarados de la revolución”.

\section{Conclusión}

Tal como este artículo lo demuestra, en las obras literarias que abordan el tema de la revolución, el comportamiento de la persona se determina por el tipo de la conciencia de la cual es portador: la conciencia colectiva o la conciencia individual. 
Estos dos tipos de conciencia coexisten dentro de un todo, pero no en condiciones de igualdad: la psicología de masas se impone a la individual. Es así como la personalidad, nivelada y desprovista de peculiaridades, se convierte en este caso en un portador de la "máscara de la revolución".

\section{References:}

1. Azuela, M. (1997). Los de abajo. New York, NY: Penguin Books.

2. Babel, Y. (2013). Konarmyya. SPb: Azbuka.

3. Kimmel, M. (1990). Revolution: A Sociological Interpretation. Philadelphia: Temple University Press.

4. Olshanskyj, D. V. (2001). Osnovy polytycheskoj psyxolohyy. Ekaterynburh: Delovaya knyha.

5. Yurevych, A. V. (2007). Psyxolohyya revolyucyj. Moskva: HU VShE. 